\title{
Novel procedure for testing of soil field test kits
}

\section{involving paper strips}

Authors: Karolina Golicz ${ }^{1}$, Stephen Hallett ${ }^{1}$, Ruben Sakrabani ${ }^{1 *}$

Affiliations: 'School of Water, Energy and Environment, Cranfield University, Cranfield, Bedfordshire MK43 0AL, UK. Email: r.sakrabani@cranfield@ac.uk

\begin{abstract}
The need for facilitation of access to soil information has never been greater. Growing human population, shrinking land and water resources, soil pollution, climate change and unequal distribution of agriculture-oriented technology impact negatively on global food security. There has been a longstanding interest in developing low-cost and easily accessible soil field kits to measure different properties of agricultural soils in order to improve their agronomic capacity. Test strips, in particular, have provided a favoured method of obtaining soil nutrient status information since the 1970s. Today there is renewed interest in using semi-qualitative colorimetric methods in soil assessment due to incorporation of modern technological solutions, such as smartphones, which could in turn increase the accuracy and precision of the existing methods. In this paper, we propose streamlined testing procedures based on experience gathered that may be conducted prior to a field kit development involving test strips. Results from laboratory and field experiments are presented, highlighting important factors which ought to be taken into account at the commencement of test-strip oriented studies.
\end{abstract}

Key words: Test strips, field test kits, soil testing methods, smartphone environmental sensing 


\section{Introduction}

Soil testing is one of the oldest and best-established tools in agricultural management (Sims et al., 2000). For decades, agronomists have used soil tests to stipulate fertiliser recommendations in order to safeguard economic viability of agricultural operations and to limit the environmental impacts associated with continuous use of commercial fertilisers (Dawson and Hilton, 2011; Gartley et al., 2002; Zhang et al., 2017). However, soil testing can prove costly, time-consuming, impractical to carry out as the crop season progresses, prone to sampling and laboratory errors, and often requiring the use of noxious chemicals as part of standard analytical procedures (Omran, 2017). These limitations can impede incorporation of soil testing as a method for soil health assessment and can further discourage agricultural workers from utilising them at the recommended time intervals. This is important as, in the UK, there is an increased emphasis on soil health (Department for Environment Food and Rural Affairs, 2020), and the means to monitor contributory soil conditions. Tools are required for such assessments that are simple to use and widely accessible to landowners.

The lack of access to effective, low-cost and site-specific alternatives to current soil testing methods has been recognised as one of the factors contributing to mismanagement of fertiliser resources (Prager and McKee, 2014). In developed countries such as the US and Australia, only about a quarter of farmers undertake soil testing, noted to be infrequent and conducted at low densities (Lobry de Bruyn and Andrews, 2016). In emerging economies, this rate is not only lower but is often arbitrary and not site-specific (Ju et al., 2009), with overfertilization being the common result, regardless of the severe consequences for agricultural productivity and the wider environment (Song et al., 2009). Recently, there has been renewed interest in creation of soil test kits optimised for agronomical field use as a result of increasing access to technology such as portable sensors (Piikki et al., 2016). Key to this is the rising ubiquity of smartphones, which are being increasingly used in environmental management applications (Aitkenhead et al., 2014) and soil science (Aitkenhead et al., 2015; Delgado et al., 2013; Stiglitz et al., 2017). 
Semi-quantitative test strips, used in combination with a reflectometer able to quantify test strip colour has been proposed as a method of quick in-field assessment of soil nutrient status in the US, Germany, Spain, and Australia (Jemison and Fox, 1988; Schmidhalter, 2005; Thompson et al., 2013; Wetselaar et al., 1998). Such strips are therefore frequently included in field soil test kits. In developing countries, in particular, they constitute a favoured way by which extension workers can collect soil information to better inform the agronomic decisions of small-holder farmers (Nyi et al., 2017). Non-governmental organisations concerned with sustainable development such as Akvo (www.akvo.org) have shown interest in utilising test strips in environmental analysis, employing smartphones to act as portable reflectometers to relate the colour of the test strip to the quantity of measured chemicals more precisely than is possible with the naked eye. This technology offers great prospects for soil testing for fertiliser recommendation purposes.

The aim of this work is to provide a comprehensive set of procedures that need consideration at the developmental stage of new in-field soil test kits involving semi-quantitative colorimetric test strips.

\section{Methods}

\subsection{Test strips and reflectometers}

The set of procedures was developed based on metadata collected across two long-term $(>2$ years long) experiments undertaken at Cranfield University, UK, where laboratory work was conducted; and Nanjing Agricultural University, People's Republic of China (PRC), where fieldwork was conducted. The UK laboratory provided the preparatory work, which supported the field study in PRC. The reason for considering field study in PRC, where soil samples were collected from smallholder vegetable farms, was due to the limited access to soil information there, resulting in sub-optimal fertiliser use and associated diminished economic returns and potential for environmental damage resulting from over-fertilisation, especially in relation to 
multi-season horticultural crops. The experiments comprise part of an ongoing study testing the viability of employing smartphones and test strips as a practicable method of soil analysis. Four test strips types were selected for use during those experiments:

- Quantofix ${ }^{\circledR}$ (reference number: 913 51) nitrate strips (range: 0-100 $\mathrm{mgL}^{-1}$ of $\mathrm{NO}_{3}{ }^{-}$);

- Quantofix ${ }^{\circledR}$ (reference number: 913 20) phosphate strips (range: 0-100 $\mathrm{mgL}^{-1}$ of $\left.\mathrm{PO}_{4}{ }^{3-}\right)$

- Quantofix $^{\circledR}$ (reference number: 913 15) ammonium strips (range: 0-400 $\mathrm{mLL}^{-1}$ of $\mathrm{NH}_{4}^{+}$); and,

- $\quad$ Merck $\mathrm{KGaA}^{\circledR}$ (reference number: 117985 ) potassium strips (range: 0-1500 $\mathrm{mgL}^{-1}$ of $\mathrm{K})$.

At the commencement of this study, another nitrate test strip (Hatch) was selected for testing, however, its production was discontinued and thus Quantofix ${ }^{\circledR}$ (reference number: 913 51) was given preference. Two types of reflectometers were employed during testing, i.e. Quantofix ${ }^{\circledR}$ Relax Test Strip Reader (Fig. 1) and Akvo Caddisfly app (ver. 10) installed on a Samsung Galaxy S8 phone. Comparison between the commercial grade reflectometer and the smartphones application will not be explored in detail in this paper. 


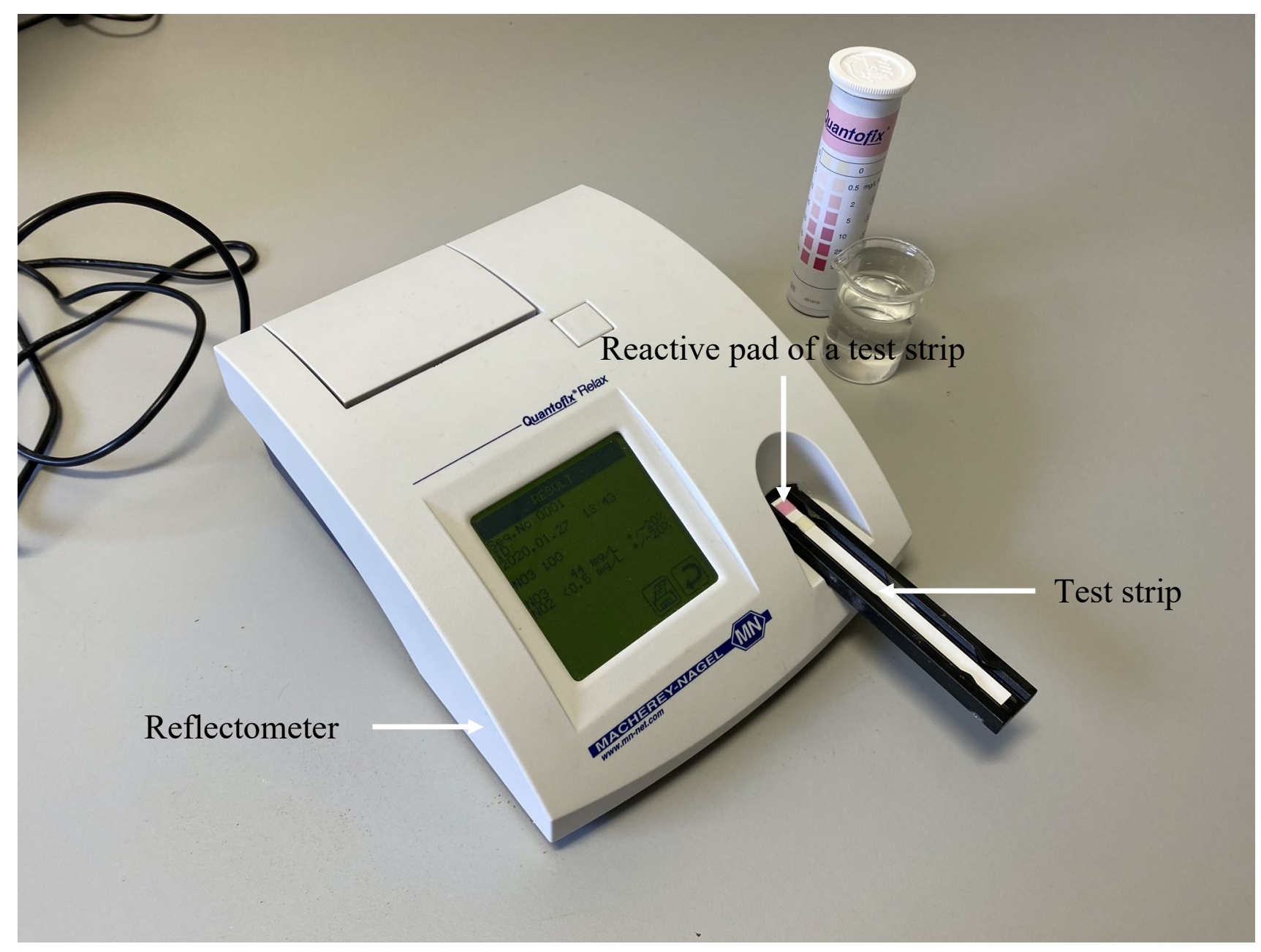

Fig 1. Test strip and reflectometer used as a method of in-field soil nutrient assessment.

As the need for accurate in-field soil nutrient measurement is particularly great amongst small holder farmers, the test strips were tested in relation to:

- How well they agreed with standard solutions;

- The standard deviation expected for readings at different concentrations;

- Interferences to colour development caused by soil test extractants;

- Sensitivity to chemical interferences likely to be encountered in the soil media and other environmental factors.

\subsection{Laboratory study}

Standards were prepared in accordance with standard operating procedures developed by Cranfield University. A set of 1000ppm stock solutions were prepared for nitrate using $6.068 \mathrm{~g}$ 
of oven-dry $\mathrm{NaNO}_{3}$ (Sigma-Aldrich, CAS number: 7631-99-4) diluted to $1000 \mathrm{~mL}, 1 \mathrm{~mL}$ of $1000 \mu \mathrm{g}$ of $\mathrm{P}$ (Fisher Scientific, Catalogue number: J829805), 3.819g of $\mathrm{NH}_{4} \mathrm{Cl}$ (Fisher Scientific, CAS number: 12125029) diluted to $1000 \mathrm{~mL}$, and 2.590g of $\mathrm{KNO}_{3}$ (Fisher Scientific, CAS number: 7757791) diluted to $1000 \mathrm{~mL}$. The stock solutions were then diluted to concentrations stipulated by the test strip manufacturer in matrix-matched solutions, which correspond to the extractants frequently used in soil analysis (Table 1).

Table 1. Stock standards diluted to concentrations stipulated by test strip manufacturers in matrix-matched solutions. Selected matrix solutions correspond to those frequently utilised in soil analysis.

\begin{tabular}{|c|c|c|c|c|c|c|c|c|}
\hline & \multicolumn{6}{|c|}{ Standards } & \multirow[t]{2}{*}{ Unit } & \multirow[t]{2}{*}{ Matrix } \\
\hline & 1 & 2 & 3 & 4 & 5 & 6 & & \\
\hline Nitrate & 5 & 10 & 25 & 50 & 75 & 100 & $m L L^{-1}$ & $\mathrm{dH}_{2} \mathrm{O}, 2 \mathrm{M} \mathrm{KCl}, 0.2 \mathrm{KCl}, 0.02 \mathrm{KCl}, \mathrm{M}-1 *$ \\
\hline Phosphate & 3 & 10 & 25 & 50 & 100 & N/A & $\mathrm{mL} \mathrm{L}^{-1}$ & $\mathrm{dH}_{2} \mathrm{O}, \mathrm{M}-1$, Olsen-P**, $\mathrm{MM}^{* * *}$ \\
\hline Ammonium & 10 & 25 & 50 & 100 & 200 & 400 & $\mathrm{~mL} \mathrm{~L}^{-1}$ & $\mathrm{dH}_{2} \mathrm{O}, 0.2 \mathrm{KCl}, 0.02 \mathrm{KCl}, 0.02 \mathrm{M} \mathrm{CaCl}_{2}$ \\
\hline Potassium & 250 & 450 & 700 & 100 & 1500 & $\mathrm{~N} / \mathrm{A}$ & $\mathrm{mL} \mathrm{L}^{-1}$ & $\mathrm{dH}_{2} \mathrm{O}, \mathrm{M}-1,1 \mathrm{M} \mathrm{NH} \mathrm{NO}_{3}$ \\
\hline
\end{tabular}

*Mehlich-1 [0.05 N HCL + $\left.0.025 \mathrm{~N} \mathrm{H}_{2} \mathrm{SO}_{4}\right]$; **Olsen-P [0.5 $\mathrm{N} \mathrm{NaHCO}_{3}$ adjusted to $\left.\mathrm{pH} 8.5\right]$, ***Modified Morgan $\left[0.62 \mathrm{M} \mathrm{NH}_{4} \mathrm{OH}+1.25 \mathrm{M} \mathrm{CH}_{3} \mathrm{COOH}\right]$

The reflectometer was used to investigate the agreement with stock solutions in distilled water $\left(\mathrm{dH}_{2} \mathrm{O}\right)$, the standard deviations associated with readings obtained via the reflectometer and the impact of different extractants on colour development on the test strips' reactive pads. The stock solutions and extractants were made on the day of measurement. Employment of test strips during testing followed the manufacturer's instructions. Readings were taken on the same day, under a constant laboratory temperature of $20.5^{\circ} \mathrm{C}$. As temperature was identified as a significant factor influencing the reaction time and thus, colour change of the test strip; a set of experiments was carried out to quantify its effect. Two test strip types, i.e. Quantofix nitrate and phosphate, were considered to have the highest potential for use in the context of soil science and thus, selected for the experiment conducted in a plant growth chamber [Weiss Technik SGR Series of Fitotron walk-in-rooms; model: SGR221 LED], which is part of the Agriculture Engineering Precision and Innovation (AgriEPI) Centre, located at Cranfield 
University. AgriEPI forms part of the national Agritech facility in the UK. The humidity was set at $70 \%$ and the investigated temperatures were: $15,20,25,30,35^{\circ} \mathrm{C}$. Solution temperature was measured with a laboratory approved thermometer to confirm it matched the ambient temperature of the plant-growth chamber. Each standard solution for nitrate and phosphate was measured with 5 test strips at every temperature setting.

\subsection{Field study}

Furthermore, consideration was given to the field-ready practicality of the soil extraction process and the lack of precision and accuracy relating to reduced access to laboratory equipment in field-conditions. Multiple soil to extractant ratios, i.e. 1:1, 1:2.5 and 1:5 were investigated with the latter having been found to be the most practical for field-use, especially in relation to heavy clays. Two soil standard reference materials (Sigma Aldrich CRM700 and CRM702) were used to investigate how dilution impacts the precision of the best performing test strip type. The samples were extracted with distilled water for 2 hours on a side-to-side shaker and then, diluted. Sample dilution factors of 2, 3.3, 5, and 10 were used, then analysed with the reflectometer. A field sample was extracted and diluted in non-laboratory conditions, as part of the field study carried out in People's Republic of China (see Golicz et al., 2019 for details) with the results of in-field dilution being compared to results of in-lab dilution.

\subsection{Statistical analysis}

Particular care is needed when employing statistical tests such as correlations and ANOVA in method comparison studies, as the bias and absolute $(\Delta)$ difference between standard laboratory and 'quick tests' might be less likely to be highlighted. Bland and Altman (2003) advocated the use of Bland-Altman (B-A) plots to investigate the degree of agreement between two methods. The B-A analysis involves constructing a scatter plot, in which the difference between the paired measurements is plotted on y-axis and average of the measures of two methods on $\mathrm{x}$-axis. The mean difference refers to the bias between two methods and is represented as a 
central horizontal line on the plot. Two additional lines are derived from the standard deviation (SD) of differences between paired measurements and represent $95 \%$ limits of agreement (mean bias 1.96 SD). This approach should be employed alongside scaling the results from $\mathrm{mg}$ $\mathrm{kg}^{-1}$ to $\mathrm{kg} \mathrm{ha}^{-1}$, which is more relevant for soil practitioners but is often overlooked in test strip studies.

\section{Results}

3.1 Laboratory-based evaluation and validation of four test strip types currently available for purchase

The agreement $( \pm \mathrm{SD})$ between four test strip types and corresponding stock standards was assessed (Table 2). Test strips developed to measure nitrate and phosphate had the highest agreement with stock standards and the lowest standard deviation associated with reflectometer readings.

Table 2. Deviation from the standard (in $\mathrm{dH}_{2} \mathrm{O}$ ). Red denotes deviation $>5$ ppm; green denotes deviation $<5$ ppm. Standard deviations of reflectometer readings for standards in $\mathrm{dH}_{2} \mathrm{O}$.

\begin{tabular}{|c|c|c|c|c|c|c|}
\hline & \multicolumn{6}{|c|}{ Standards (in $\left.\mathrm{dH}_{2} \mathrm{O}\right)$} \\
\hline & 1 & 2 & 3 & 4 & 5 & 6 \\
\hline & \multicolumn{6}{|c|}{ Deviation from the standard [Mean, $\mathrm{N}=5$ ] } \\
\hline Nitrate & 2 & 0 & 0 & -2 & -2 & 0 \\
\hline Ammonium & -7 & 1 & -15 & -83 & -92 & 0 \\
\hline Phosphorus & 3 & 0.6 & -3.6 & -1.2 & 0 & $\mathrm{~N} / \mathrm{A}$ \\
\hline \multirow[t]{2}{*}{ Potassium } & -42 & -58 & -50 & -70 & -213 & -230 \\
\hline & \multicolumn{6}{|c|}{ Standard deviation of reflectometer readings $[\mathrm{STDV}, \mathrm{N}=5]$} \\
\hline Nitrate & 2.1 & 0.9 & 2.5 & 3.3 & 4.0 & 0 \\
\hline Ammonium & 5.0 & 2.0 & 2.0 & 22.0 & 31.0 & 0 \\
\hline Phosphorus & 0.6 & 0.6 & 4.6 & 2.6 & 0.0 & $\mathrm{~N} / \mathrm{A}$ \\
\hline Potassium & 7.6 & 2.9 & 7.6 & 4.0 & 11.4 & 0 \\
\hline
\end{tabular}

The level of agreement between test-strips and stock standards was reduced when a soil extractant was utilised as a matrix (Fig. 3A-D). Highly concentrated extractants were found to cause severe interferences with colour development in all test strip types. Interferences were also noted for extractants with low molar concentrations, such as Mehlich-1 $(0.05 \mathrm{M} \mathrm{HCl}$ in $\left.0.025 \mathrm{M} \mathrm{H}_{2} \mathrm{SO}_{4}\right)$ and $0.02 \mathrm{KCl}$, with distilled water consistently providing the best results. 

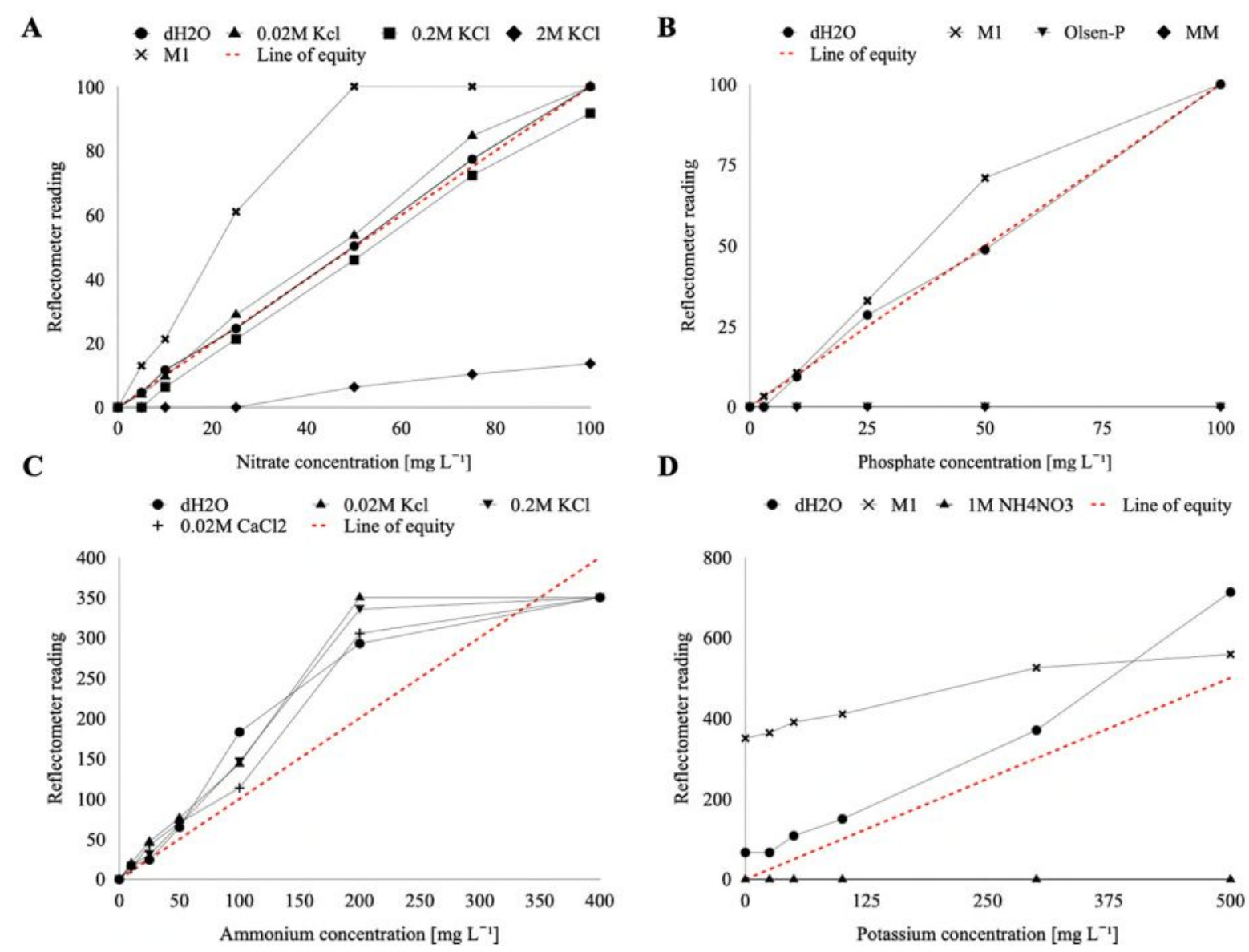

D
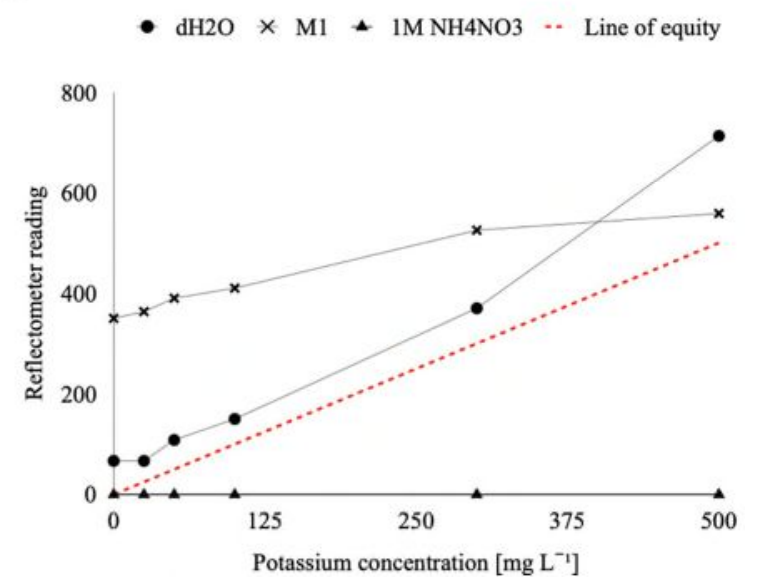

Fig. 2A-D. Impact of extractants on four commercial test strip types used for the measurement of nitrate (A), phosphate (B), ammonium (C) and potassium (D).

Furthermore, test strips were found to be susceptible to environmental factors, particularly temperature effects. At high temperatures, the concentration of measured chemical present in the solution is severely overestimated e.g. at $35^{\circ} \mathrm{C}$, reflectometer readings overestimate standard concentration by $25 \mathrm{mg} \mathrm{L}^{-1}$ for $\mathrm{NO}_{3}{ }^{-}$(Fig 4A) and $30 \mathrm{mg} \mathrm{L}^{-1}$ for $\mathrm{PO}_{4}{ }^{3-}$ (Fig 4B).
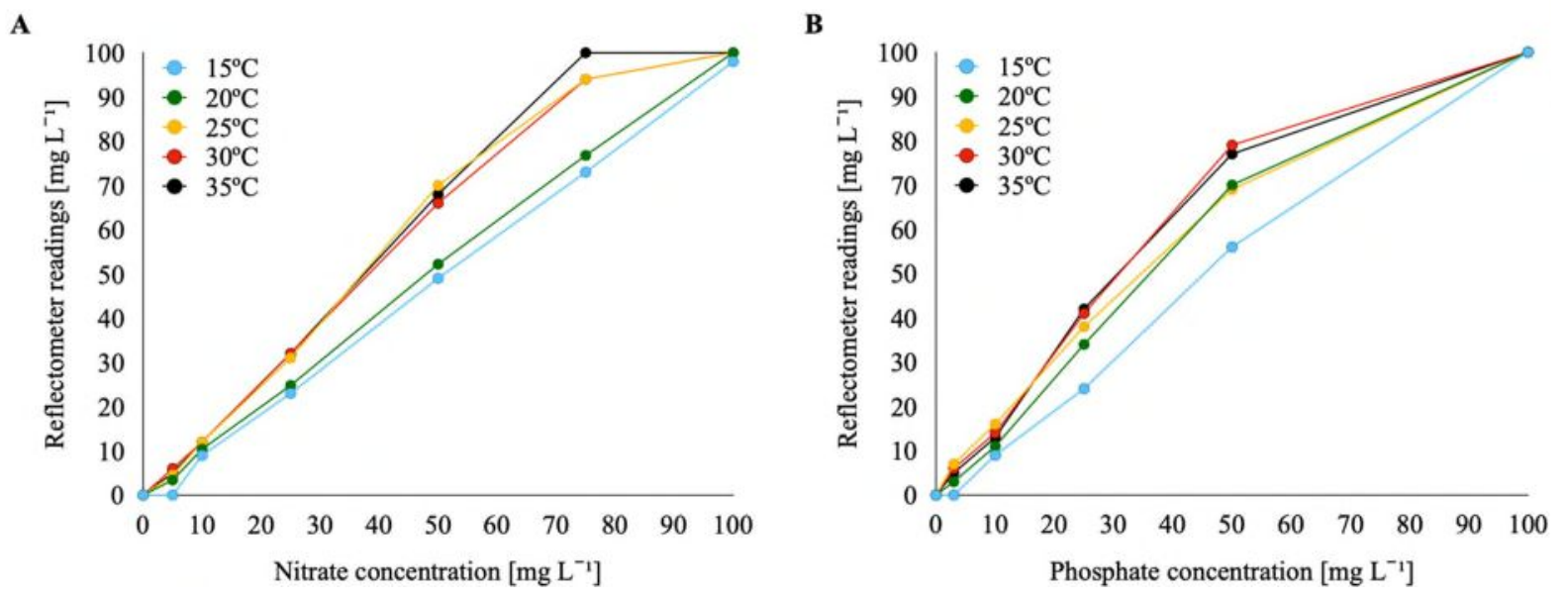
Fig. 3A-B. Impact of temperature on test strip colour development and subsequent reflectometer reading. At high temperatures the readings are overestimated.

\subsection{Insights from field experiments}

When recently fertilised fields were sampled, test strips with low range, i.e. 0 to $100 \mathrm{~mL} \mathrm{~L}^{-1}$ of $\mathrm{NO}_{3}^{-}$, required dilution. Dilution was shown to be effective in the laboratory environment where access to suitable equipment is facilitated (Fig 4A), but it reduced the accuracy of the method in the field conditions (Fig 4B).

$\mathbf{A}$

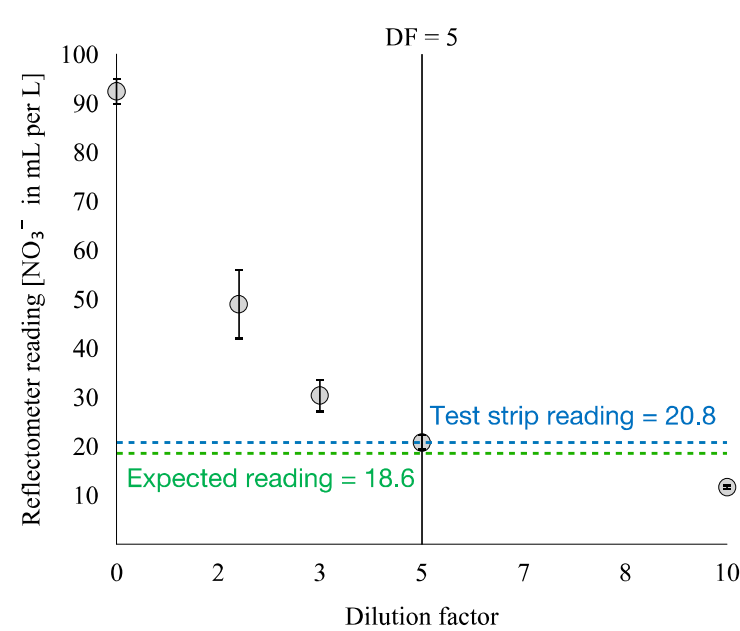

B

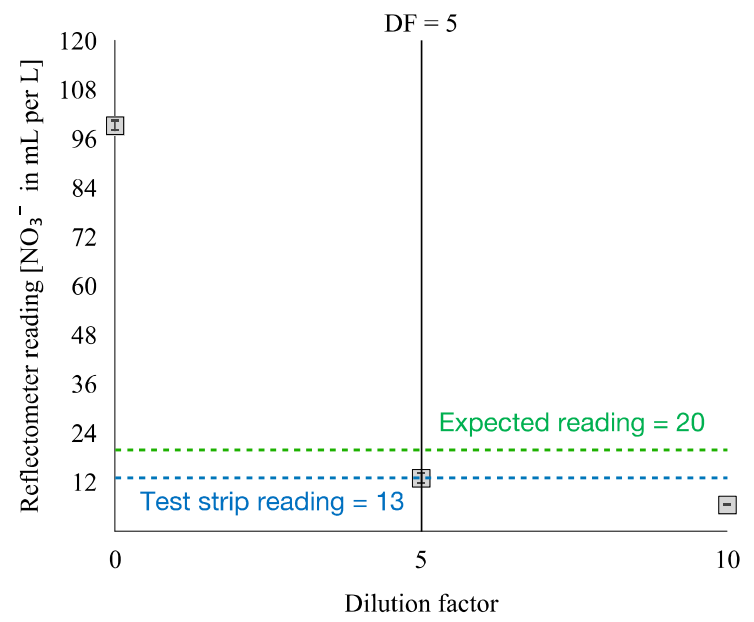

Fig. 4A-B. In-lab dilution vs in-field dilution, and its effect on the reflectometer readings' accuracy.

Similarly, whereas filtration in controlled laboratory conditions is allowed to take up to a few hours when soil to extractant ratio is high, this approach was highly impractical in field conditions (Fig 5A). Furthermore, during field trials, multiple issues with hardware i.e. the reflectometer were identified, including: (1) low resistance to humidity, (2) high battery consumption, and (3) abrasion caused by sand (Fig. 5B). 


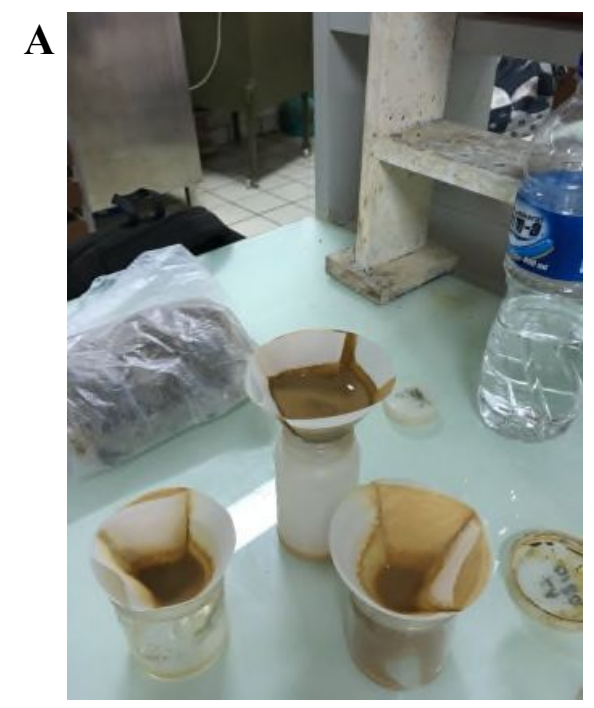

Impractical soil to extractant ratio

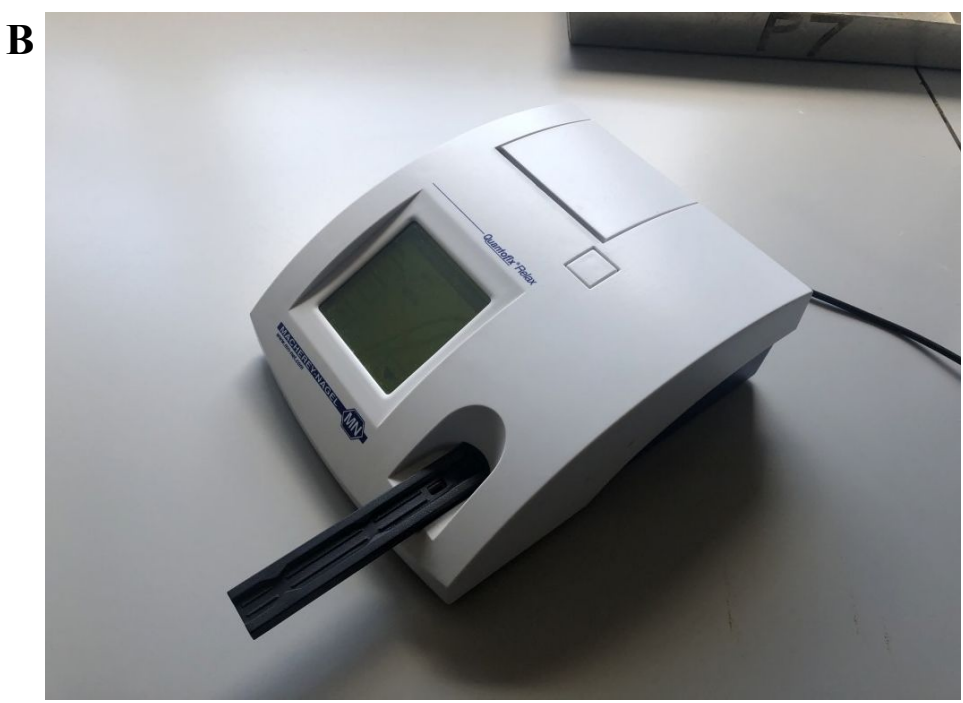

1. Expensive; 2. Low resistance to humidity / radiation; 3. High battery consumption; 4. Abrasion caused by wind / sand; 5. Hard to get replacement parts; 6 . Works with limited test strips types

Fig. 5A-B. Factors to be considered during the planning stage of a field study designed to test the accuracy and precision of soil field test kits. Field experiments might expose unexpected issues with equipment and methodology that would not have been noted in a study conducted in controlled laboratory conditions.

\subsection{Proposed procedure for preliminary testing of soil field test kits involving paper strips}

Multiple variables were investigated to optimise choices for selection of soil field test kit apparatus during laboratory and field studies, which considered the viability of employing semi-quantitative colorimetric test strips in soil analysis. As the experiments were conducted throughout two years alongside other studies, there was a limited sequence to the actions taken.

Formulation of new methodologies for test strip use (for detailed examples see Hartz, 1994 and Jemison \& Fox, 1988) will always involve an element of trial-and-error. A summary of organised actions designed to streamline testing procedures is described in Fig. 6.

This set of procedures is presented as a decision support tool and was derived from the laboratory and field studies and field observations. Each step can be considered separately or as a sequence of steps aimed at identifying limitations at the developmental stage of new infield soil test kits involving paper strips. 


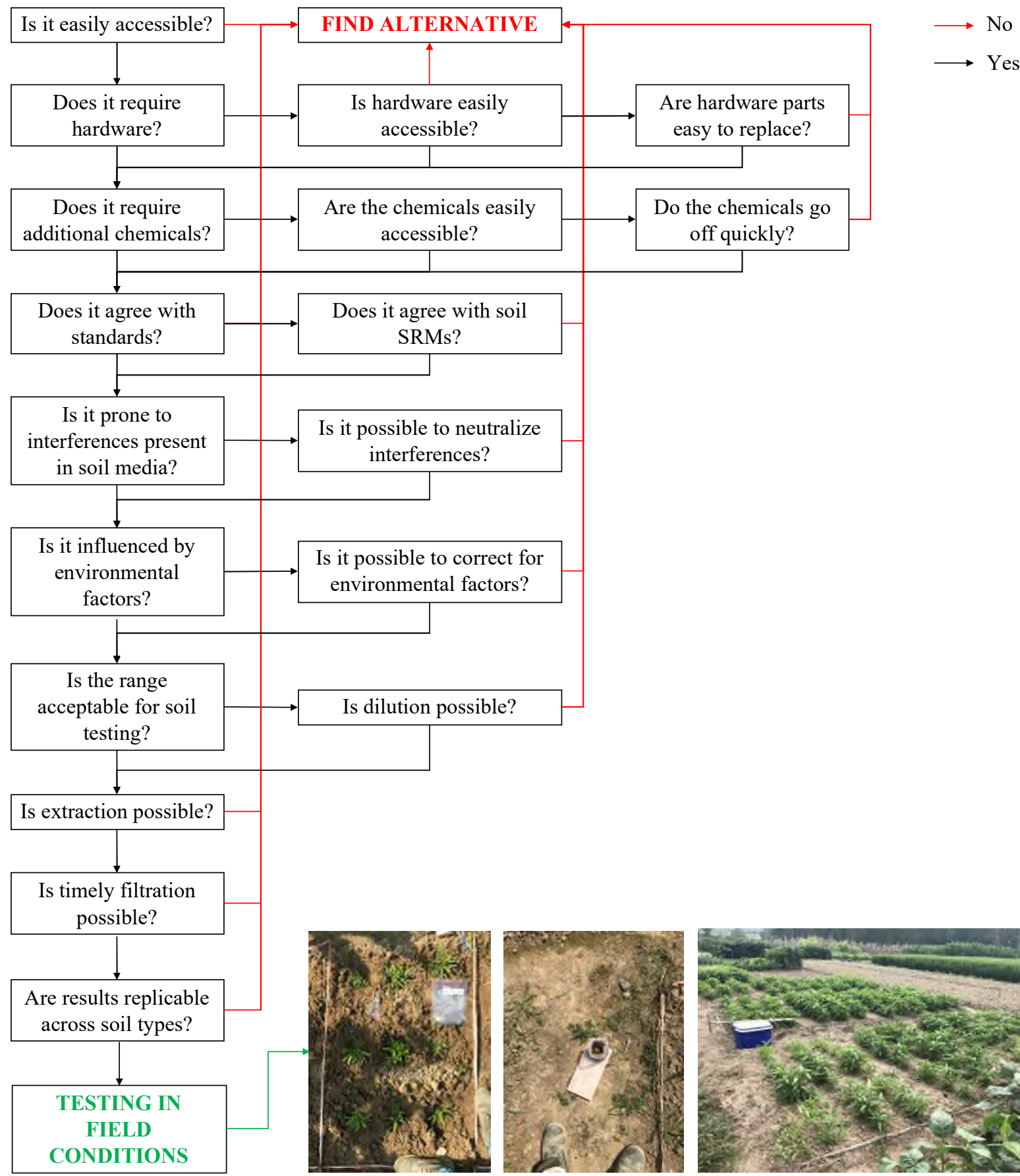

Fig. 6. Proposed testing sequence of laboratory experiments to be undertaken as part of field test kit development. Terms used: SRM - soil reference material; additional chemicals encompass chemicals required for the test strip reaction to occur, and chemicals used during the extraction process; environmental factors refer primarily to temperature and humidity.

\subsection{Limitations of current statistical methods used in method comparison studies}

Table 3 shows a subset of results presented in test strip-oriented studies conducted between 1988 and 2018. WebPlotDigititizer (ver. 4.2) was used to extract the results from published 
charts. The errors, defined as the difference between the standard method and the test strip method, ranged between $19.9 \mathrm{mg} \mathrm{kg}^{-1}$ and $-55.7 \mathrm{mg} \mathrm{kg}^{-1}$ or $35.9 \mathrm{~kg} \mathrm{ha}^{-1}$ and $-100.2 \mathrm{~kg} \mathrm{ha}^{-1}$ (assuming a sample depth of $15 \mathrm{~cm}$ and a bulk density of $1.2 \mathrm{~g} \mathrm{~cm}^{-3}$ ), regardless of the reported range of $\mathrm{R}^{2}$ values between 0.94 and 0.97 .

Table 3. Selected subset of results from test-strip studies conducted between 1988 and 2018. Results obtained from published charts with WebPlotDigititizer (ver. 4.2). Difference between measurement is calculated by subtracting the value obtained via the test strip result from the value obtained via the standard method.

\begin{tabular}{|c|c|c|c|c|c|}
\hline Reference & $\begin{array}{l}\text { Standard } \\
\text { method }\end{array}$ & Test strip & $\begin{array}{l}\text { Difference } \\
{\left[\mathrm{mgxkg}^{-1}\right]}\end{array}$ & $\begin{array}{l}\text { Difference } \\
{\left[\text { kgxha }^{-1}\right]}\end{array}$ & $\begin{array}{l}\text { Reported } \\
\mathrm{R}^{2} \text { values }\end{array}$ \\
\hline \multirow[t]{7}{*}{ Hartz, 1994} & 131.6 & 113.9 & 17.7 & 31.9 & \multirow[t]{7}{*}{$\mathrm{R}^{2}=0.94$} \\
\hline & 71.5 & 90.6 & -19.0 & -34.3 & \\
\hline & 65.6 & 82.0 & -16.4 & -29.4 & \\
\hline & 46.1 & 59.0 & -12.9 & -23.2 & \\
\hline & 58.9 & 40.9 & 18.0 & 32.5 & \\
\hline & 25.9 & 31.5 & -5.6 & -10.0 & \\
\hline & 36.0 & 16.1 & 19.9 & 35.9 & \\
\hline \multirow{7}{*}{$\begin{array}{l}\text { Wetselaar et al., } \\
1998\end{array}$} & 57.6 & 60.7 & -3.0 & -5.4 & \multirow[t]{7}{*}{$\mathrm{R}^{2}=0.957$} \\
\hline & 43.5 & 32.8 & 10.7 & 19.3 & \\
\hline & 36.7 & 30.1 & 6.6 & 11.9 & \\
\hline & 30.9 & 26.3 & 4.6 & 8.3 & \\
\hline & 2.7 & 5.6 & -2.9 & -5.3 & \\
\hline & 13.7 & 11.3 & 2.4 & 4.3 & \\
\hline & 10.1 & 11.5 & -1.4 & -2.5 & \\
\hline \multirow{7}{*}{$\begin{array}{l}\text { Schmidhalter, } \\
2005\end{array}$} & 78.3 & 88.5 & - & -10.2 & \multirow[t]{7}{*}{$\mathrm{R}^{2}=0.966$} \\
\hline & 70.9 & 54.3 & - & 16.7 & \\
\hline & 34.0 & 19.3 & - & 14.7 & \\
\hline & 20.9 & 4.4 & - & 16.5 & \\
\hline & 26.7 & 38.4 & - & -11.7 & \\
\hline & 59.6 & 45.3 & - & 14.3 & \\
\hline & 72.7 & 58.2 & - & 14.6 & \\
\hline \multirow[t]{8}{*}{ Loo et al., 2017} & 185.0 & 175.0 & 10.0 & 17.9 & \multirow[t]{8}{*}{$\mathrm{R}^{2}=0.96$} \\
\hline & 84.0 & 139.7 & -55.7 & -100.2 & \\
\hline & 62.5 & 96.2 & -33.7 & -60.6 & \\
\hline & 42.5 & 77.7 & -35.2 & -63.3 & \\
\hline & 22.5 & 44.2 & -21.7 & -39.0 & \\
\hline & 122.0 & 147.4 & -25.4 & -45.7 & \\
\hline & 92.5 & 126.8 & -34.3 & -61.7 & \\
\hline & 63.5 & 52.6 & 10.9 & 19.6 & \\
\hline
\end{tabular}




\section{Discussion}

\subsection{Insights from laboratory work}

Assessment of the agreement between test strips and stock standards alongside estimation of acceptable limits for standard deviation (SDs) of readings should be conducted at the beginning of any test-strip oriented study. This will facilitate the choice of the best strip types for further work. Furthermore, if SDs are high at higher concentration, this information can be used to inform the methodology selected, e.g. by extracting lower quantities of soil but incorporating dilution factors. Ideally, test strips should be also checked against soil standard reference material (SRM) following initial testing with stock standards in $\mathrm{dH}_{2} \mathrm{O}$. SRM contains a series of compounds, which can be found in the soil media at concentrations likely to cause interference with the colour development of the test strip's reactive pad. By using SRM for quality assurance of colorimetric strips, those that are highly sensitive to interference can be replaced with an alternative in a timely manner.

Test strips constitute a form of chromatography and thus, are intrinsically prone to chemical interference (Xie et al., 2013). Potential interferences are stipulated in the instruction manual provided by the manufacturer, e.g. nitrite is identified as interference-causing agent for Quantofix ${ }^{\circledR}$ strips (test strip reference number: 913 51) and silica is identified as interferencecausing agent for Quantofix ${ }^{\circledR}$ strips (test strip reference number: 913 20). Both cause overestimation of readings, however, only the former's impact on the test strips' colour development can be easily discerned and thus neutralized (Wetselaar et al., 1998). It is also essential to consider the combinatorial effects of chemicals, e.g. the impact of individual substances might have been investigated by the manufacturer and specified in the manual, combining chemicals even at low concentrations can result in unexpected interferences to colour development of the reactive pad. An example is when even low-concentration 
extractants such as Mehlich-1 $\left(0.05 \mathrm{M} \mathrm{HCl}\right.$ in $\left.0.025 \mathrm{M} \mathrm{H}_{2} \mathrm{SO}_{4}\right)$ or $0.02 \mathrm{KCl}$ were shown to have an impact on the agreement with standards.

\subsection{Insights from fieldwork}

The accessibility of equipment such as reflectometers and test strips themselves requires careful consideration as selecting expensive or niche products, which require additional support in the form of removable parts or chemical compounds, might make the final product more difficult to use by interested parties. For example, Aguilera, Motavalli, Gonzales, \& Valdivia (2014) reported issues with in-field application of Cardy nitrate meters in the highlands of Bolivia due to limited access to the standard solutions necessary to calibrate the tool. Similarly, over the course of this study, production of one of selected test strip types was discontinued. Additionally, certain test strips, e.g. Quantofix phosphate and ammonium test strips, might be supplied together with the chemical reagents necessary for the reaction to take place. It is considered essential to obtain the required amounts of chemicals and assess the likelihood of impact by time since opening and/or environmental factors such as temperature before commencement of any field-based experiments. The latter remains true for any potential extractant. In field conditions, weather might be unpredictable and high ambient temperatures could render certain solvents unusable.

Another factor, which impacts performance of test strips, involves environmental variables such as temperature and humidity. Temperature, in particular, affects the rate of reaction (Schmidhalter, 2005), which results in lower colour intensity at lower temperatures, and higher colour intensity at higher temperatures. Different test strips might require separate temperature correction factors and thus, should be investigated separately prior to any field study.

Finally, development of an in-field test kit involves an iterative learning process. Conducting experiments and analysis in the field conditions will result both in the discovery of unexpected 
drawbacks in the proposed analytical procedure, and the implementation of further improvements to the method. For example, it is essential to consider extraction, filtration and replicability of any proposed methodology across different soil types, especially with regard to soil texture. In laboratory conditions, extraction can be facilitated through the use of consistent mechanical shakers, whereas in field conditions manual shaking might prove to be limited by the user's physical ability. Filtration in controlled laboratory conditions might take up to a few hours when soil to extractant ratio is high, as proposed in, e.g. Jemison \& Fox, 1988; but this approach would be highly impractical in field conditions. If an extractant is to be used; its impact on the test strip accuracy has to be accounted for and its longevity and accessibility considered in full. As lightly textured soils (sands and sandy loams) are easy to extract and filter, they should not be used to guide method development, with heavy clays being given a priority during final stages of in-field soil test kit evaluation. Finally, if a reflectometer is to be used, then it is important to consider certain factors e.g. low resistance to humidity and dust, high battery consumption or difficulties in replacement of internal parts, that might make it impossible for use in field conditions.

\subsection{Application of an appropriate statistical methodology to establish operational limits of}

\section{agreement between field test kit and standard soil analytical methods}

Robust statistical methods need to be employed to ensure that the results obtained via the infield soil test kit can be used to inform management activities on farms or in similar settings. The most commonly used statistical methods in papers promoting test strips are regressions and correlations. However, these two methods look at the degree of association, not agreement (Bland and Altman, 2003). High correlation coefficients might obscure the lack of agreement between two methods expressed as high mean difference bias, unequal distribution of errors, e.g. greater differences at higher concentrations or vice versa, making it more difficult to assess the nature, size and frequency of errors. Alternative statistical approaches such as Bland- 
Altman plots (Bland and Altman, 2003; Phatak and Nimbalkar, 2017) can be used to highlight the differences between two methods and help either to modify an existing methodology or to adopt a more critical approach regarding test strip application in soil and plant tissue analysis. Papers that describe the use of in-field soil test kits ought to focus on the agreement between methods and associated operational limits, i.e. the point where the errors are too large to be of practical use for agronomic management purposes, whilst taking into account the need for sample replication. Furthermore, the variability of soil testing methodologies between laboratories, regions and countries must be considered. Therefore, more than one method of soil analysis should be employed to compare the results, in order to ensure transferability across regions. If the results agree only with certain country-specific methods, then, more suitable alternatives might have to be sought.

\section{Conclusions}

Results obtained from experiments, involving test strips, conducted in the laboratory and field conditions were used to highlight important factors that are likely to influence the precision and accuracy of in-field soil analytical methods. The compilation of results allowed for development of a novel procedure for preliminary testing of soil field test kits involving paper strips. We have emphasised the need to employ robust statistical methodologies to explore and compare data obtained via the in-field and standard methods of soil analysis has been emphasised in order to improve current approach to assessment of practical limits to the use of in-field soil testing method.

Conflict of Interests: The authors declare no conflict of interest.

Acknowledgements: The authors wish to acknowledge Akvo.org for facilitating funds for conducting test strip testing. This work was supported by the UK Natural Environment Research Council [NERC Ref: NE/M009009/1]. Data underlying this study is made accessible through Cranfield University's repository at https://10.17862/cranfield.rd.11193668. 


\section{References}

Aguilera, J., Motavalli, P., Gonzales, M., Valdivia, C., 2014. Evaluation of a Rapid Field Test Method for Assessing Nitrogen Status in Potato Plant Tissue in Rural Communities in the Bolivian Andean Highlands. Commun. Soil Sci. Plant Anal. 45, 347-361. https://doi.org/10.1080/00103624.2013.857680

Aitkenhead, M.J., Donnelly, D., Coull, M.C., Hastings, E., 2014. Innovations in environmental monitoring using mobile phone technology - a review. Int. J. Interact. Mob. Technol. 8, 50-58.

Aitkenhead, M.J., Donnelly, D., Sutherland, L., Miller, D.G., Coull, M.C., Black, H.I.J., 2015. Predicting Scottish topsoil organic matter content from colour and environmental factors. Eur. J. Soil Sci. 66, 112-120. https://doi.org/10.1111/ejss.12199

Bland, J.M., Altman, D.G., 2003. Applying the right statistics: Analyses of measurement studies. Ultrasound Obstet. Gynecol. https://doi.org/10.1002/uog.122

Dawson, C.J., Hilton, J., 2011. Fertiliser availability in a resource-limited world: Production and recycling of nitrogen and phosphorus. Food Policy 36, S14-S22. https://doi.org/10.1016/j.foodpol.2010.11.012

Delgado, J.A., Kowalski, K., Tebbe, C., 2013. The first Nitrogen Index app for mobile devices: Using portable technology for smart agricultural management. Comput. Electron. Agric. 91, $121-123$.

Department for Environment Food and Rural Affairs, 2020. Agriculture Bill. London.

Gartley, K.L., Sims, J.T., Olsen, C.T., Chu, P., 2002. Comparison of soil test extractants used in midAtlantic United States. Commun. Soil Sci. Plant Anal. 33, 873-895. https://doi.org/10.1081/CSS-120003072

Golicz, K., Hallett, S.H., Sakrabani, R., Pan, G., 2019. The potential for using smartphones as portable soil nutrient analyzers on suburban farms in central East China. Sci. Rep. 9, 1-10. https://doi.org/10.1038/s41598-019-52702-8 
Hartz, T.K., 1994. A quick test procedure for soil nitrate-nitrogen. Commun. Soil Sci. Plant Anal. 25, $511-515$.

Jemison, J.M., Fox, R.H., 1988. A quick-test procedure for soil and plant tissue nitrates using test strips and a hand-held reflectometer. Commun. Soil Sci. Plant Anal. 19, 1569-1582. https://doi.org/10.1080/00103628809368035

Ju, X.T., Xing, G.X., Chen, X.P., Zhang, S.L., Zhang, L.J., Liu, X.J., Cui, Z.L., Yin, B., Christie, P., Zhu, Z.L., Zhang, F.S., 2009. Reducing environmental risk by improving N management in intensive Chinese agricultural systems. Proc. Natl. Acad. Sci. U. S. A. 106, 8077. https://doi.org/10.1073/pnas.0902655106

Lobry de Bruyn, L., Andrews, S., 2016. Are Australian and United States Farmers Using Soil Information for Soil Health Management? Sustainability 8, 304. https://doi.org/https://doi.org/10.3390/su8040304

Nyi, T., Varughese, P., bin Hj Bujang, M.I., Ra, K., Irianta, B., Sengxua, P., Sipaseuth, N., Harirah, A.A., Bin Jantan, B., Salguero, S.M., Meunchang, P., Manh Quyet, V., Quang Hai, N., Moody, P., Jäkel, T.E., Soda, W., 2017. ASEAN Guidelines on Soil and Nutrient Management. Bangkok.

Omran, E.-S.E., 2017. Will the Conventional Soil-Plant Analysis Pass into Oblivion? Rapid and Low-Cost Determination Using Spectroscopy. Commun. Soil Sci. Plant Anal. 48, 705-715. https://doi.org/10.1080/00103624.2017.1298782

Phatak, A.G., Nimbalkar, S.M., 2017. Method comparison (agreement) studies: Myths and rationale. J. Clin. Diagnostic Res. https://doi.org/10.7860/JCDR/2017/23897.9314

Piikki, K., Söderström, M., Eriksson, J., John, J.M., Muthee, P.I., Wetterlind, J., Lund, E., 2016. Performance evaluation of proximal sensors for soil assessment in smallholder farms in Embu County,Kenya. Sensors (Switzerland) 16. https://doi.org/10.3390/s16111950

Prager, K., McKee, A., 2014. Use and awareness of soil data and information among local 
authorities, farmers and estate managers 16.

Schmidhalter, U., 2005. Development of a quick on-farm test to determine nitrate levels in soil. J. Plant Nutr. Soil Sci. 168, 432-438. https://doi.org/10.1002/jpln.200520521

Sims, J.T., Edwards, A.C., Schoumans, O.F., Simard, R.R., 2000. Integrating Soil Phosphorus Testing into Environmentally Based Agricultural Management Practices. J. Environ. Qual. 29, 60-71. https://doi.org/10.2134/jeq2000.00472425002900010008x

Song, X.Z., Zhao, C.X., Wang, X.L., Li, J., 2009. Study of nitrate leaching and nitrogen fate under intensive vegetable production pattern in northern China. Comptes Rendus - Biol. 332, 385392. https://doi.org/10.1016/j.crvi.2008.11.005

Stiglitz, R., Mikhailova, E., Post, C., Schlautman, M., Sharp, J., Pargas, R., Glover, B., Mooney, J., 2017. Soil color sensor data collection using a GPS-enabled smartphone application. Geoderma. https://doi.org/10.1016/j.geoderma.2017.02.018

Thompson, B.R., M, P.F., Gallardo, M., Peña-Fleitas M, T., 2013. Improved nitrogen management practices for vegetable production Improving N Management - General Considerations, in: Karoline D’Haene, Bart Vandecasteele, Raf De Vis, Sara Crappé, Danny Callens, Els Mechant, Georges Hofman, S.D.N. (Ed.), NUTRIHORT : Nutrient Management, Innovative Techniques and Nutrient Legislation in Intensive Horticulture for an Improved Water Quality. Book. Ghent, p. 388 .

Wetselaar, R., Smith, G.D., Angus, J.F., 1998. Field measurement of soil nitrate concentrations. Commun. Soil Sci. Plant Anal. 29, 729-739. https://doi.org/10.1080/00103629809369980 Xie, C., Xu, J., Tang, J., Baig, S.A., Xu, X., 2013. Comparison of Phosphorus Determination Methods by Ion Chromatography and Molybdenum Blue Methods. Commun. Soil Sci. Plant Anal. 44, 2535-2545. https://doi.org/10.1080/00103624.2013.811518

Zhang, B., Li, Q., Cao, J., Zhang, C., Song, Z., Zhang, F., Chen, X., 2017. Reducing nitrogen leaching in a subtropical vegetable system. Agric. Ecosyst. Environ. 241, 133-141. 
https://doi.org/10.1016/j.agee.2017.03.006 